\title{
Emergent Narratives in Remote Learning Experiences for Project Based Education
}

\author{
Moritz Philip Recke and Stefano Perna \\ University of Naples Federico II, Italy \\ moritzphilip.recke@unina.it \\ stefano.perna@unina.it
}

\begin{abstract}
The University of Naples Federico II (Italy) offers a nine-month formative training program aimed at software development for the Apple technology ecosystem to 400 learners per year and utilises the Challenge Based Learning (CBL) methodology as a framework for learning. As a collaborative and self-guided, inquiry-based learning method, it focuses on learners' intrinsic motivation while working on real world problems organised in projects (Challenges in CBL) with an experiential and progressive approach to apply acquired knowledge in real world scenarios, ideate solution concepts and build innovative digital products. To overcome limitations of spiral curriculum or elaboration theory, the authors applied narrative theory to design the program's educational experience for the academic year 2019/2020 as a cohesive journey within a communal learning environment with a coherent and connected structure of narratively driven learning Challenges. The authors present concepts to develop their approach further towards an emergent narrative experience design system to manage the educational journey as it develops, rather than scripting it. This paper evolves the authors' Narrative Experience Design Canvas to model educational experience design that encourages unscripted, emergent narratives for experiential education with the goal of fostering learners' engagement, agency and creativity. Derived in part by models developed for digital interactive storytelling or educational video games, it categorises the components for designing an educational experience that allows the learning progression to be driven by learners as co-authors and describes mechanisms that allow unscripted narratives to emerge based on intrinsic motivation. Additionally, the authors present considerations for synchronous and asynchronous learning to evolve their framework for application in blended or remote learning scenarios. Drawing upon findings for remote learning and experiential e-learning - ee-learning - presented by scholars as well as implications identified during the COVID-19 pandemic and the resulting switch to remote learning within the program at University of Naples Federico II in 2020, it is shown how combining narrative elements with experiential e-learning principles can result in increased engagement, motivation and sense of community in learners. Using the example of an individual learning unit - a Challenge - considerations from overall course design down to day-to-day learning activities within the course are presented. For the future, the authors indicate action points to develop this model into an Emergent Narrative System for designing narratively driven and experiential software development education programs and indicate areas of further research on learning activity design for blended or remote learning experiences.
\end{abstract}

Keywords: emergent narrative, learning experience design, challenge based learning, narrative theory, experiential elearning, remote learning

\section{Introduction}

The University of Naples Federico II (Italy) offers a nine-month formative training program aimed at software development for the Apple technology ecosystem and utilises the Challenge Based Learning (CBL) methodology as a framework for learning (Nichols \& Cator 2008, Johnson et al. 2009, Johnson \& Brown 2011). The annual program for $\sim 400$ learners evolves around collaboration and self-guided, inquiry-based learning while learners work on real-world problems, called Challenges in $C B L$, both individually and in groups. It is differentiated from other learning frameworks by its strong emphasis on learner engagement. The learning experience can be described as a guided immersion into reality that drives learner's intrinsic motivation to acquire knowledge required to complete Challenges, which is represented in the Engage phase of the CBL process.

Prior to the academic year 2019/2020, the program was designed along principles of spiral curriculum or elaboration theory (Reigeluth 1979, 1999, 2012). While learning goals were presented with logical relationships between topics and a linear movement from simple to complex, the individual learning units were designed as a sequence of unconnected and separate Challenges. To better foster individual and collective engagement within learning units, the author's research is aimed at developing a learning design framework to support educators in creating a learning environment that provides the needed flexibility for learners to take control of their learning journey as they co-create the experience in a learning community. To this effect, the authors employed narrative theory to better connect between Challenges and introduced a narrative layer for the overall experience design for academic year 2019/2020 (Recke \& Perna 2020a). for Project Based Education. The Electronic Journal of e-Learning, 19(2), pp. 59-70, available online at www.ejel.org 
The resulting narrative approach follows a temporal and experiential rather than logical scheme and therefore constitutes an interconnected sequence of narratively driven learning Challenges, which is in line with Matthews' (2018) recommendations for sequencing learning experiences and Parrish's (2009) consideration of narrative dramatic organisation of experiences as the most engaging and effective sequence. To address findings that narrative sequencing does not guarantee an experience as intended or designed (Matthews 2018), the approach also incorporated a large degree of learner autonomy to shape the individual learning journey within the program. Since Gray (2015) established that learning experiences cannot be designed deterministically, the narrative arcs and characteristics of the learning environment have been designed with strong emphasis on fostering learners' intrinsic motivation and engagement (Malone 1981, Malone \& Lepper 1987). Inducing a sense of ownership and agency and incorporating learners as co-authors in the narrative progression are among main aims of such an approach. The new narrative experience design has prevailed and evolved since its first implementation and especially during the COVID-19 pandemic to incorporate considerations from overall course design down to day-to-day activities within the course.

Using the example of an individual learning unit - a Challenge - within the program, this paper elaborates on interactive narrative concepts presented by the authors (Recke \& Perna 2020b) that can be used to design the educational experience for the program aimed at software development for the Apple technology ecosystem through affectively driven, emergent narratives. Instead of organising sequential learning goals, the authors propose organising experiences that create an overarching narrative within which the learning goals are achieved as learners engage with Challenges in the learning environment and affectively drive the narrative progression as co-authors. Furthermore, the approach is extended with concepts devised from findings by scholars on remote learning and experiential e-learning - ee-learning - to incorporate considerations for blended and remote learning scenarios the authors identified during the COVID-19 pandemic in 2020 (Recke \& Perna 2020c). The need was to develop a systematic model for learning experience design that considered both synchronous and asynchronous learning dimensions in the experiential education program. The described approach was applied in academic year 2019/2020 with a cohort of $\sim 400$ learners and continuously adapted during the evolving COVDID-19 pandemic in 2020 until the academic year ended. While concluding evaluation is still ongoing, initial findings already led to an evolution and additional extension of the narratively driven experience design approach towards blended learning as a persistent paradigm for upcoming academic years. The authors present considerations for further development and indicate aspects of continuous evaluation and assessment for more systematic investigation.

\section{Storytelling and Emergent Narratives in Education}

Scholars have consistently showcased the significance of storytelling in education. It allows to emotionally engage students with learning objectives and strengthen their comprehension and capacity to learn (Woodhouse 2001, Silbermann 2006, Jarrett 2019). Furthermore, storytelling is well-suited to support inquirybased and project-based learning (Skouge \& Rao 2009), such as within the CBL framework used in the program at University of Naples Federico II. In experiential learning, aimed at engaging learners in its activities, storytelling is key in connecting experiences to subsequent experiences, according to Dewey (1938). In this perspective, experiential learning fosters this process of inquiry, recognising the interconnectedness of world and experience, also emphasising the value that emotions, aesthetics, ethics, and not only knowledge, play into the process itself. Consequently, learning experiences have aesthetic qualities that need to be designed in order to create an immersive, coherent and complete result that learners engage with, respond to, influence and draw from (Parrish 2009). Key aesthetic qualities are intellectual and emotional tension, rhythm and sequence, which are directly connected to narrative sequences and patterns that can be employed in inquiry-based approaches to create tension, mystery and resolution (Parrish 2009). Therefore, narrative structure provides a framework of representation that is natively and intuitively understood by anyone (Fiore, Metcalf \& McDaniel 2007) to describe key characteristics of learning experiences and can provide meaningful interpretation of stories learners live through (Woodhouse 2001). The cognitive process of organising experiences with narrative form can be employed in active learning and allows for the creation of interactive narratives, where students can create or influence the dramaturgy through their actions (thereby creating meaningful consequences), immersing them into the world of the story (Riedl \& Bulitko 2012).

Interactive and emergent narrative concepts show that stories cannot just be authored, displayed or enacted in classical ways, but also emerge directly from interactions between different actors under specific conditions and create themselves from relationships between its elements (Aylett 1999, Aylett et al. 2006, Louchart \& Aylett 
2004). In that sense the story is not consumed by an audience but experienced, lived through and even more so driven by it. The narrative unfolds through interwoven threads of tension, causal links, affective decisions, personalities and priorities (Aylett et al. 2006), most of which are inherent to characters within the story, resulting in many enacted storylines rather than a single storyline that different actors need to conform to. Recent research in this area largely focuses on interactive narrations, e.g. digital games or simulations. Wu et al. (2011) found a strong connection between experiential learning theory and game-based learning. Looking more in detail at the connection between the role of narrative between games and learning, Gee (2003) argued that narrative design in games provides support for problem solving and allows players/learners to assume roles and become embodied agents in the game experience. In this line of inquiry, the work of Malone (1981) and later Provenzo (1991) and Rieber (1996) identified the element of fantasy, or narrative, as one of the key elements in games that support intrinsic motivation. More recently scholars started identifying elements in narrative game design that can be borrowed and adapted to design learning environments (Prensky 2001, Squire 2003, Dickey $2006,2011)$. Dickey (2006) showed to what extent game design narrative can provide insights into how and why carrying the narrative through an activity might enhance learning and learner's motivation, also providing a set of design guidelines and heuristics for the application of game narrative in instructional design. These concepts have also high relevance for designing an experiential educational environment in the view of the authors. An environment that allows longer-term emergent narratives to develop around learners can create a tacit and personal dimension of learning and can intrinsically motivate learners to dive deeper into the course with actual ownership of the learning experience (Malone 1981, Malone \& Lepper 1987).

Some authors highlighted a narrative paradox in gaming and interactive storytelling, where a conflict arises between storytelling's traditional linearity and the multilinear experience of gaming and interactive storytelling (Göbel et al. 2009, Lindley 2002, 2005, Louchart \& Aylett 2004) which leads to a different role and conceptualisation of both the author and the audience. Göbel et al. $(2008,2009)$ and Göbel \& Mehm (2013) further explored the theme and identified different strategies to integrate plot-based storytelling and non-linear interactive approaches. Interactive and emergent narratives drastically change the authoring dimension towards roles, environments, props, relationships and a global vision of the experience rather than linear plot, thereby creating a world that characters interact in and formulating setup of situations likely to trigger characters into engaging in potentially dramatic ways, acting and decision making (Aylett et al. 2006). Controlling such narratives requires an evaluative feedback loop that analyses the emergent plot in regard to its narrative progression and potentially adjusts conditions of the world (Gervás 2009, Berov 2017). In creation of unscripted narratives, affect is considered essential as it creates dramatically relevant action selection and corresponding expressive behaviour needed to induce characters' motivation to act (Aylett et al. 2006). Within a performative experience of an unscripted narrative, emotional systems serve as the narrative engine for characters and affect motivation from one episode's emotional state to the other (Louchart \& Aylett 2004), interconnecting parts of the narrative like memory. The authors propose an application of these principles in the educational environment of the program at University of Naples Federico II, where the emergent narrative is performed by learners, teachers and other stakeholders. It allows unscripted narratives, affectively driven by its characters, to emerge naturally within the educational context of the formative program aimed at software development for the Apple technology ecosystem.

\section{Learning Experiences in Remote Scenarios}

The formative program discussed here is highly experiential in nature and rooted in real-world experience and problems, enacted in relationship with peers, instructors and educational spaces. Therefore, it is key to not undermine the engagement of the learners on cognitive, behavioural and affective levels in a remote learning environment. To also provide a robust and effective learning experience in remote learning scenarios, the authors draw on recent findings from scholars that tried to define theoretical frameworks and concrete strategies through which experiential learning can be applied successfully online.

In line with the authors' overall experience design approach, Lindgren \& McDaniels (2011) show that the explicit integration of narrative and consideration of student agency can have a positive impact on online instruction. Most particular, the field of experiential e-learning - ee-learning - draws its core concepts from Dewey's (1938) principles of continuous interplay between experience and learning as well as Freire's (1970) dialectical interactions between students and teachers (Baasanjav 2013, McFarland 2017). Consequently, learners' experiences are elemental and should encourage learners to face real world problems and give them agency 
over the educational process in an online environment (Carver et. al. 2007, Beard, Wilson \& McCarter 2007, Riedel et al., 2007, Trevitte \& Eskow 2007, Murphrey 2010).

Along this line of thinking, specific areas are considered critical in ee-learning course design, such as personalisation of interactions (Coombs-Richardson 2007, Lalonde 2011), learner-learner/learner-teacher interaction and learners' involvement with stakeholders (McCrory, Putnam \& Jansen. 2008, Lalonde 2011) and opportunities for learners to be self-directed and self-motivated (Schott et al. 2003, Rivera \& Rice 2002, Wong 2007). Additional core concepts of learner centredness, agency and belongingness should be considered in eelearning as Carver et al. (2007) identified. Online education should shift gravity from teachers to learners and change the role of teachers into the role of mentors as facilitators of the learning process (Carver et al. 2007, Kennedy 2004, Murphrey 2010). It should offer learners flexibility and control over their learning process, thereby being learner-centered, as they can choose when, where and how they learn (Carver et al. 2007, Huang 2002, Knowlton 2000, Shin \& Le, 2009, Baasanjav 2013). By providing learners with the ability to take action and make deliberate choices in their learning journey, they become actors with full ownership for their learning process (Carver et al. 2007, Baasanjav 2013) and develop agency though self-directed learning, time management, overcoming anxiety and frustration etc. (Weinstein, Meyer, \& Husman 2006), while interacting with other learners and teachers that share the responsibilities of the learning process. Most critically however, promoting belongingness is key to overcome learner isolation as one of the key challenges in remote learning (Carver et al. 2007, Huang 2002). To this effect a mix of communication strategies and platforms with multiple forms of connectivity and dialogue between teachers and learners can support learners' sense of belonging and build trust among peers (Smyth 2011). Most effectively, a community of practice among learners can be developed through a combination of synchronous and asynchronous toolchains in which learners collaborate and share their individual and communal experience (Carver et al. 2007, Huang 2002, Murphrey 2010).

\section{A Narrative Experience Design Canvas for Learning Experience Design}

Benefits of applying narrative-like arcs and dramatic patterns to the design process of educational experiences, courses and classes have already been highlighted (Parrish 2009, Matthews 2018). Tools and methods from fields of experience design and narrative design have been proposed as an expanded toolset for instructional designers and educators (Matthews 2018). Dickey (2006) showed how concepts and principles derived from narrative game design can be extended and applied to learning environments, both physical and virtual.

Narrative theory shows that people perceive complex relationships in forms of narrative structures that connect cause-and-effect relationships to sequences of events (Polkinghorne 1988, Fludernik 2009). Scholars in this field identified recurring patterns behind a broad category of stories throughout different cultures and historical periods. Beyond many variations of the model existing, which may include different articulations in narrative phases and blocks, one of the most acknowledged and recurring structures is the 3 acts structure - act 1: setup; act 2: confrontation; act 3: resolution - that can be traced back to Aristotle and still plays a central role in contemporary screenwriting (Field 2005, Vogler 1998). Vogler's model in particular has been adapted beyond the boundaries of literary writing and extended to the design of narratives in interactive and online media such as games (Dickey 2006). Parrish (2009) argues that narrative-like structures can inform the design of learning experiences and in particular points to the 3 acts structure, suggesting that heightened, aesthetic learning experiences have narrative-like beginnings, middles, and ends.

In line with this perspective, a 3 acts narrative-like structure is used in the formative program at University of Naples Federico II to articulate the learning experience at the meta-level of the overall program design (Recke \& Perna 2020a), at the level of single units of learning (Recke \& Perna 2020b) as well as in granular learning activities. The meta narrative ensures that few specific fundamental articulations and turning points are put into place and experienced by a vast majority of learners in the learning environment. It provides basic articulations of the overall learning experience into broad narrative phases or Acts - beginnings, middles and ends -, and ensures that specific narrative turning points - such as cathartic events and transitions between phases - will be taken into account in the sequencing process. A similar structure is then used to design specific learning Challenges, connecting the individual unit's narrative to the overarching storyline. With a recursive approach also individual learning activities within the learning units are subject to narrative sequencing and can be utilised to drive and support learner agency. To this effect a typology of learning activities is used to classify the function of individual activities within the Challenge and overall narrative progression. 
To support the design process for learning units, the authors created a Narrative Experience Design Canvas that helps ideating and planning the learning experience while considering 2 design dimensions: 1) the learning layer encompassing learning goals, content, activities, pedagogical approaches, individual/collaborative learning strategies, expected outcomes and deliverables; 2) the narrative layer that addresses how the learning experience unfolds in time according to emotional arcs, including important plot points, dramatic events and quests, with the overall aim of fostering learners' engagement and agency (Recke \& Perna 2020b). In consideration of recent findings for remote learning and experiential e-learning presented by scholars as well as implications identified during the COVID-19 pandemic and the resulting switch to remote learning within the program at University of Naples Federico II in 2020, the authors evolved the Narrative Experience Design Canvas to be more considerate of asynchronous and synchronous events within the narrative progression as well as significantly more granular in the sequencing process (Figure 1).

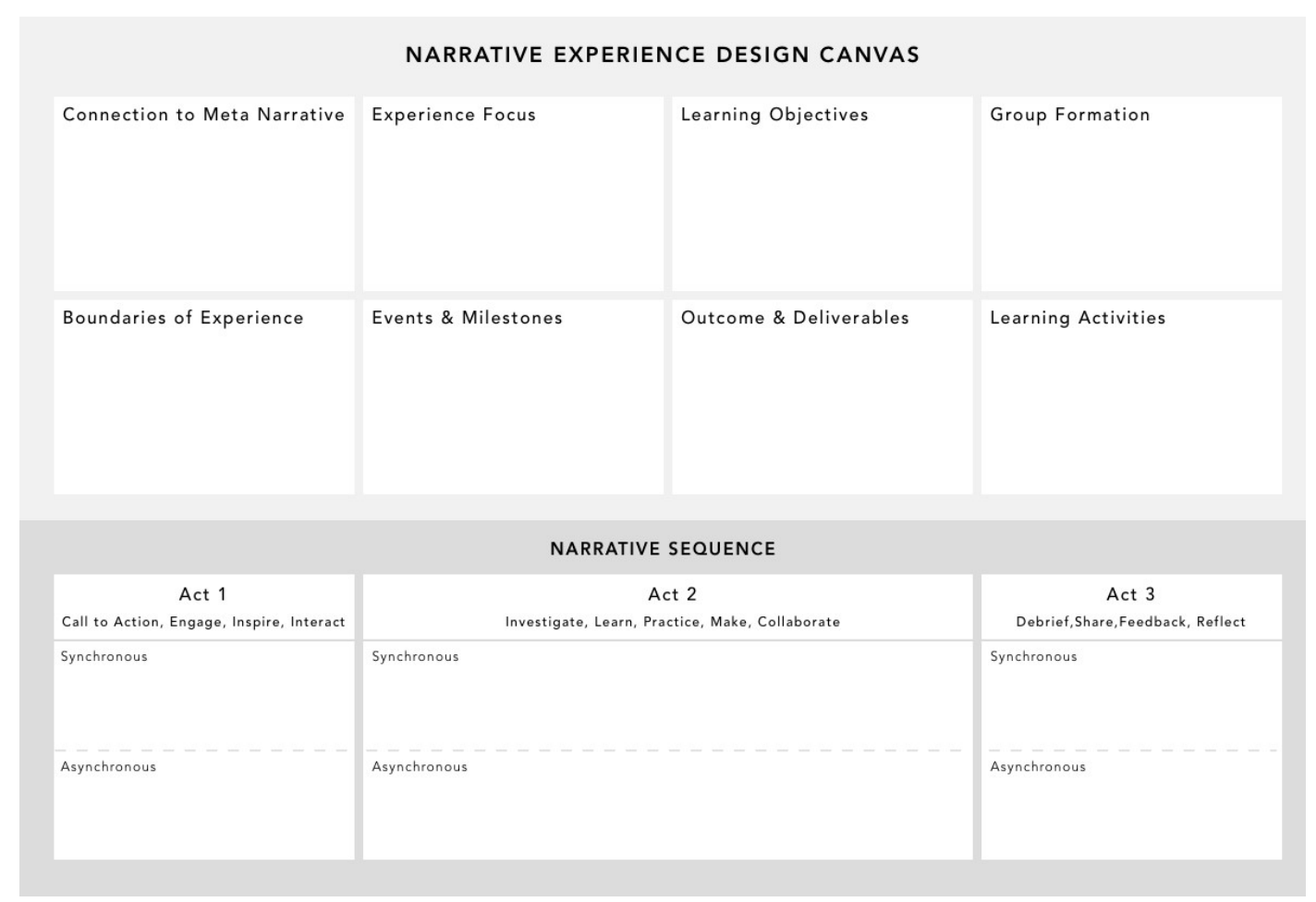

Figure 1: Narrative Experience Design Canvas (version 2)

In line with principles derived from the backwards design approach to instructional design (Wiggins \& McTighe 2005), the canvas allows learning designers to "start form the end" by defining first overall goals, outcomes and evidence of learning to be produced and then articulating and planning the learning experience with all its components and details, including both the cognitive and the affective dimensions. As the narrative unfolds and progresses, the design process is highly iterative and recursive and also better supported in the canvas evolution that is now mainly used within collaborative online editors for asynchronous ideation and Challenge design.

The Narrative Experience Design Canvas helps connecting the narrative experience of the single learning unit to the overarching narrative meta-level of the program. Additionally, it connects the day-to-day learning activities to an interconnected sequence of events that adopts a narrative structure of the Challenge and can be effected over time by students affective decision making. Learning activities itself can not only be placed in a sequence but also adopt a narratively driven design approach on their own. In consequence, this results in different learning activities serving very divergent needs within the learning experience from a narrative perspective. Adopting a typology to support learning dimensions to inspire learners to explore topics of their choosing; providing room for them to exercise their newly acquired skills and create artefacts as evidence of learning; encouraging them to share their knowledge with peers; these are all elements that support learner autonomy and agency in shaping their individual learning journey while working in groups in their Challenges.

The Narrative Experience Design Canvas and design process briefly described above connect the program's individual learning unit of a Challenge to the overarching narrative without pre-scripting how the entire 
Challenge unfolds. Narratively designed learning activities further support the narrative progression and enactment of learners' divergent storylines. Addressing concerns about intended and deterministic experience design presented above (Gray 2015, Matthews 2018) and borrowing concepts from emergent and interactive storytelling in interactive media and games, such as integration of Vogler's model for storytelling in non-linear media (Göbel et al. 2009, Göbel \& Mehm 2013) and insights from emergent narrative systems (Aylett et al 2006), the presented approach allows the Challenge progression to be largely driven by learners. They are given a high degree of freedom in defining important aspects of the learning process, while overarching cohesion is ensured through introduction of specific boundaries and wide story phases. Such boundaries and phases are aimed at supporting an overall sense of coherence between experiential units, dramatic tension, meaningful events and turning points that are critical aspects for the perceived value of a story. In this perspective, learners are pushed to act as co-narrators and can be described as co-authors of the narrative along with the Challenge designers. Being free to define parts of the learning objectives, projects, skills they want to build and the collaboration strategies to use, learners are empowered to take ownership of their learning process and therefore of the specific and personal story they experience.

\section{Application of Emergent Narratives in Remote Learning}

Building on the shift towards an entirely remote learning scenario for the program during the COVID-19 pandemic in early 2020 (Recke \& Perna 2020c), the authors extended the narrative experience design described above systematically and embedded the principles of ee-learning (Carver et. al. 2007) in the overall curriculum design to evolve the framework towards blended learning.

As an example of a designed narrative unit in the afore mentioned context, a Challenge designed and executed during the second Act of the meta narrative can be considered. The first Act and its related Challenges are designed to function as prologue and catalyst for a new way of learning, facilitating the transition for the learners from their previous context, the ordinary world of "traditional" education - made of highly structured curriculum, syllabus and lectures - to the new model of learning proposed by the $C B L$ framework, based on ownership, self-regulation, inquiry, collaboration and creativity. The second Act is rather designed as an intermediate stage of tensions, surprises and increased complications that modulate learners' engagement (Parrish 2009). In this phase Challenges progress at different paces and depths and introduce progressions that may provide turns, jumps, multiple paths, uphill and downhill inclines (Matthews 2018) that provoke and stimulate learner agency. The Challenge discussed here serves to push learners to build upon previously acquired knowledge and make some important choices about developing higher and deeper skills towards a more individualised and customised learning journey.

These characteristics of the learning unit can be projected on a diachronic axis to provide the Challenge with narrative tension that may foster engagement and immersion. This is where the 3 acts structure comes into play also at the level of the specific Challenge and not only at the meta-level of the program. The Challenge is provisioned with a diverse set of triggers, designed to activate different and even contrasting affective reactions in learners, and additional triggers to highlight transitions between the different stages. In the beginning, learners are presented with "dramatic" events - or Call to Actions - that ask them to get out of their comfort zones and make a choice among a pre-designed list of 16 different Paths to work on individually or in remotely collaborating groups in highly divergent tracks of topic areas that can be augmented through learners' own decision making. Strong emphasis is given to freedom of choice, customisation and self-driven autonomy, in line with ee-learning scholars' recommendations about learners' personalisation and agency. Also, the group formation strategies are open and learners are free to team up based on commonalities of interests and to define their own remote collaboration environments, schedules and workflows.

As the Challenge unfolds into the middle act, other triggers such as learning activities and external domainexperts' interventions are presented in order to give learners the opportunity to reinforce the skills in the area they decided to challenge themselves. Divergent paths through the Challenge are encouraged and further supported through a variety of parallel, independent and at the same complementary learning activities to inspire learners and provide room for them to exercise, create and share. Learning activities are sequenced within the Challenge to support different levels of existing knowledge, interests and motivations as well as different learning modalities (such as synchronous or asynchronous), speeds and dimensions. Ultimately, the divergent approach to activity formats supports learner agency and co-authorship in the narrative progression while ensuring certain turning points to be reached within time and with appropriate results. 
During the middle act, group events and community dynamics such as mid-term reviews, peer-feedback sessions, small public presentations are used to build and release narrative tension. The fact that this specific Challenge, with its components of individual choice and customisation, happens in a remote setting highlights the need to counterbalance the centrifugal push that such a granular level of personalisation would produce, with the risk of resulting in a too disconnected and isolated experience for the learners. Some strategies are put into place to follow another fundamental principle of ee-learning which is promoting a sense of belongingness in a connected community of peers. While each track is organised independently with separate groups, divergent deliverables, consultations and other practices to individually engage learners in their projects, different communication toolchains are adopted to create discussion groups, collaborative workspaces, wikis, workshops, video conferences or audio/video recordings that may be consumed synchronously or asynchronously, both at the level of small groups of collaborators and of the whole community of learners.

In the third and ending act of the Challenge, events that are most relevant in terms of emotional tension are placed, such as final deadlines and presentations with external reviewers, reaching the climax of the narrative arc. Other elements of "community convergence" are also introduced at this later stage of the Challenge towards the "epilogue" in narrative design terms - to reunite the overall learning community after returning from their divergent paths. These elements are designed to celebrate their accomplishments and share consumable artefacts as evidence of learning, e.g. editorial articles, videos, graphic assets, tutorials or shared code repositories in forms of an exhibition among the community of practice that would foster discussion and feedback sessions. Personalisation and customisation on one side and belongingness, community and connectedness on the other are orchestrated in the online scenario to support learners' engagement and motivation both at the cognitive and affective level.

In the last part of the third act, learners are given opportunities to engage in metacognitive practices of reflection and journaling, project retrospectives and post-mortems and supervised self-assessment, facilitating a mental detachment from the completed Challenge and fostering a deliberate action approach towards the next narrative arc, with the aim of promoting their sense of narrative presence (Rowe et al. 2007).

Beyond the design of the Challenge and its multiple tracks, the overall approach to narratively driven learning design revealed to be relevant also at the level of specific learning activities that are crafted to support different levels of prior knowledge, interests and individual space/time needs. Such a multilayered and multilinear learning experience design requires a highly differentiated "palette" of learning activities that could leverage multiple learning modalities and approaches and support learner agency and active engagement. The differentiation has to take into account not only the space/time dimension (synchronous/asynchronous) but also different learning types and strategies that might better fit specific needs at specific phases and/or turning points throughout the narrative experience. Drawing on Laurillard's (2012) conversational framework and its 6 learning types (acquisition, investigation, discussion, collaboration, practice, production), different learning activities "formats" were identified by the authors to serve differentiated needs, depending on the specific path and the specific positioning in the narrative sequence of the Challenge. As an example, synchronous remote activities that foster live collaboration on digital realtime whiteboards are designed to practice specific technical skills and remote collaboration abilities, while asynchronous activities that involve acquisition and investigation of new knowledge are designed with the purpose of letting learners dive deeper into specific topics at their own pace and level of depth, both individually and in small group settings.

This approach to learning activity design fits well into the open-ended and dynamic nature of the narratively designed Challenge, which requires high levels of customisation and just-in-time activity creation, and opens the way for an expanded repertoire of formats of activities which can be adapted to the emergent dynamics of a not-scripted narrative, where co-authorship and co-ownership are highly valued. Under this perspective the narrative design approach revealed to be promising also at the granular level of specific learning activity design. The learning types taxonomy of Laurillard's framework and its integration into a design process inside the $A B C$ learning design methodology by Hasenknopf et al. (2019) were integrated by the authors with the 3 acts structure embodied in the Narrative Design Canvas described above into some early experiments, providing a framework to design specific learning activities for blended scenarios which are highly focused on learner agency and affective/aesthetic engagement. Such framework for activity design proved to be promising and deserves further investigation. 


\section{Discussion \& Implications}

The introduced experience design approach employs both narrative theory and elements of narrative game design to articulate the experiential educational program aimed at software development at University of Naples Federico II. With the new design applied in academic year 2019/2020, learning goals and individual Challenges were introduced in a significantly more consistent and interconnected fashion, following not a conceptual-logical but a temporal and experiential scheme, which is in line with Matthews (2018) recommendations for sequencing learning experiences. This is further substantiated by Parrish (2009) who considers narrative dramatic organisation of experiences as the most engaging and effective sequence. To account for arguments that narrative sequencing does not guarantee a defined experience (Matthews 2018) that can therefore not be designed deterministically (Gray 2015), also individual learning units of the program - the Challenges - were designed with the narrative approach embedded in the Narrative Experience Design Canvas to create an episodic sequence of progression that interconnects events within the learning environment down to the level of day-today learning activities. A large degree of autonomy was given to learners to co-create the experience and drive the narrative progression within a Challenge. Connecting the Challenge to the meta narrative ensured key plot points to occur within the learning unit to drive the overall narrative progression. In designing the narrative layers and characteristics of the environment, strong emphasis was given to fostering learners' intrinsic motivation and engagement (Malone 1981, Malone \& Lepper 1987) to induce the sense of ownership and agency. The inherent freedom of choice in designing specific learning paths became the central notion of the evolved learning experience. The new narrative experience design introduced is therefore in line with academic findings.

The narrative layer of the experience was dynamically remodulated during the COVID-19 pandemic in 2020, considering findings by Lindgren \& McDaniels (2011) to show that elements of narrative and storytelling are effective in enhancing the experiential dimension of online education, and Carver et al. (2007) to align on principles of learner-centeredness, agency and belongingness for effective ee-learning. The degree of individualisation and customisation within Challenges has been increased significantly in the learning experience design process and learners were given the ability to choose topics areas to explore, learning pace and resources, while teachers adopted roles as mentors and facilitators, in line with findings by scholars (Huang 2002, Knowlton 2000, Carver et al. 2007, Shin \& Lee 2009, Baasanjav 2013). The evolved experience design aimed at increasing learner's flexibility to define their learning process and learning modalities to reinforce self-regulation in terms of Bandura (2001). As co-authors of their individual learning journey, learners' agency was programmatically supported though narrative elements that interconnect learning activities, learning units and the overall sequence of Challenges as parts of a bigger story as suggested by Lindgren \& McDaniels (2011). Learners' sense of belongingness within a community of practice has been addressed through a set of tools, activities and communal events, such as peer-feedback, knowledge sharing, $Q \& A$, group projects presentations and debriefings, community celebration, that were provided both synchronously and asynchronously to enable divergent modalities of learner-learner and learner-teacher interactions as suggested by scholars (Carver et al. 2007, Huang 2002, Smyth 2011).

The authors explored concepts from narrative game design and storytelling in order to address the inherent non-linear and unscripted nature of a real world, embodied narrative learning experience. Emergent narratives concepts derived from the field of digital games and simulations are borrowed to evolve the presented experience design approach even further. Building on the idea that narratively driven experiences cannot just be authored, a hybrid of plot-based and unscripted dynamics (Göbel \& Mehm 2013) is required to let the enacted narrative experience emerge directly from the interactions between different protagonists or actors under specific conditions and create themselves from relationships between its elements (Louchart et at. 2004, Aylett 2006). As a result, the experience can be lived through and even more so driven by learners, resulting in many enacted storylines rather than a single storyline that different learners need to conform to.

Further research is needed however to support learner autonomy and agency even better. To understand how learners affect and contribute to the experience, deep empathetic understanding and analysis of the learners are needed (Cates \& Bishop 2003, Parrish 2014, Matthews 2018). To evolve the narrative experience design approach developed by the authors, the program needs to be equipped with suitable sensing mechanisms to analyse and understand the learners' journey through the program in close to realtime. Most importantly, systematic feedback loops have to be developed for these sensing mechanisms to evaluate and control the emergent plot in regard to its narrative progression. These feedback loops should then inform appropriate 
measures to make adjustment as they become necessary within the narrative system (Gervás 2009, Berov 2017). Even though many mechanisms to sense the current state of developments have been established within the tools, activities and reflective practices described above, a drastic acceleration towards real time feedback loops with immediate impact on the adjustment layer of the experience design would be beneficial.

The authors also presented the possibilities of merging existing learning design methodologies with the narrative design approach, in particular the six learning types framework by Laurillard (2012) and the ABC learning design workshop (Hasenknopf et al.) to extend the potentialities of the narrative design approach to the granular level of specific day-to-day learning activities.

A systematic evaluation of both qualitative and quantitive results is still ongoing and can be shared in subsequent publications. Still, some initial findings can already be asserted. Considering preliminary results in terms of tangible artefacts, delivered projects and portfolio items created by learners during the remote Challenges, the authors are confident that the adopted strategies had a positive impact on learners' experience as well as outcomes. Taking the example of the described Challenge above, quantitative evaluation shows that the diversity of topic areas explored by learners at their own discretion has grown significantly compared to the previous year and also the number of elective editorial artefacts produced has increased drastically from 58 long form articles to 252. In qualitative dimensions the created editorial content as evidence of learning through teaching others has also clearly outperformed the previous year, as is evidenced by some learners' editorial content being adopted by major publications on platforms such as Medium among other indicators. The number of mobile apps published by learners on the App Store increased by $25 \%$, which is also a qualitative rather than quantitive indicator as the obstacles to overcome in achieving this learning outcome are considerable. This highlights a new level of qualitative output that was not achieved before.

However, in order to better evaluate the results of such an approach in terms of learning outcomes and learners' experience, an extension of the assessment strategies within the program's learning environment, currently based on a mix of self-, peer- and co-assessment approaches as described by Sluijsmans, Dochy \& Moerkerke (1998), is also required.

\section{Conclusion}

The authors have presented their narratively driven experience design approach for the experiential education program aimed at software development for the Apple technology ecosystem at University of Naples Federico II. In addition to the previously presented overarching narrative layer for the academic year 2019/2020 (Recke \& Perna 2020a) and the introduction of the Narrative Experience Design Canvas (Recke \& Perna 2020b), this paper further elaborated how to design and implement individual learning units - Challenges in CBL - in an interconnected sequence of narratively driven experiences that follow a meta narrative and incorporate learner's as co-creators of their learning journey. Additionally, the authors presented how to incorporate individual learning activities in the narrative experience design approach and highlighted how it can be adapted for blended and remote learning scenarios through deep consideration of synchronous and asynchronous learning dimensions. By combining their narrative experience design approach with ee-learning principles, the authors presented ways to increase learner engagement, motivation and sense of community and thereby contribute to the discussion on experiential learning in remote and online learning scenarios.

Preliminary insights from academic year 2019/2020 indicate that the presented learning experience design is valid and in line with academic findings on narratively driven experiential education. Authors are confident that the overall learning experience designed through the described approach is adding to the previously described narrative experience design. Even though final evaluation is still being worked on, it is already showing improved results both in terms of learning outcomes and learner's perceived experience if compared to previous academic years.

With the evolution towards deeper integration with experiential e-learning principles and adaptations for blended and remote learning scenarios, the authors established a strong foundation for a learning design framework for designing and implementing narratively driven learning experiences for embodied, remote or blended learning scenarios. Beyond systematic evaluation of the described approach, further research by the authors is aimed at evolving the presented approach and incorporating latest findings for remote learning into a systematic model for experience design. Through the use of emergent narrative concepts, the educational 
experience could be designed as even less pre-scripted but rather affectively driven by learners and evolve into an Emergent Narrative System. To incorporate a systematic approach to narratively driven learning activity design, subsequent publications are aimed at presenting the overall model as well as additional canvases as planning tools to support the course and learning activity design process and constitute a comprehensive framework for designing educational experiences.

\section{Acknowledgements}

This work was conducted at the Apple Developer Academy in Naples (Italy), operated in collaboration between University of Naples Federico II and Apple Inc., where the authors are faculty members.

\section{References}

Aylett, R. (1999) "Narrative in Virtual Environments - Towards Emergent Narrative", Proceedings of the Am. Assoc. for Artificial Intelligence (AAAI) Fall Symposium on Narrative Intelligence 1999, AAAI Press, pp 83-86.

Aylett, R. et al. (2006) "Unscripted narrative for affectively driven characters", IEEE Computer Graphics and Applications, Vol. 26, No. 3, pp 42-52.

Baasanjav, U. (2013) "Incorporating the experiential learning cycle into online classes", Journal of Online Learning and Teaching, Vol. 9, No. 4, pp 575-589.

Bandura, A. (2001) "Social cognitive theory: An agentic perspective", Annual Review of Psychology, Vol. 52, pp 1-26.

Beard, C., Wilson, J.P. \& McCarter, R. (2007) "Towards a Theory of E-learning: Experiential e-learning", Journal of Hospitality, Leisure, Sport and Tourism Education, Vol. 6, No. 2, pp 3-15.

Berov, L. (2017) "Character Focused Narrative Models for Computational Storytelling", AAAI Conference on Artificial Intelligence and Interactive Digital Entertainment, North America, Sep. 2017.

Carver, R., King, R., Hannum, W., \& Fowler, B. (2007) “Toward a model of experiential e-learning”, MERLOT Journal of Online Learning and Teaching, Vol. 3, No. 3, pp 247-256.

Cates, W.M. \& Bishop, M.J. (2003) "Learner as Bobsled Operator: The Physics of Learner Engagement", Journal of Educational Technology Systems, Vol. 31, No. 3, pp 291-305.

Coombs-Richardson, R., (2007) “Personalizing Distance Learning”, Kappa Delta Pi Record, Vol. 43, No. 2, pp 71-75.

Dewey, J. (1938) Experience And Education, Reprint (1997), Touchstone, New York.

Dickey, M.D. (2006) “Game Design Narrative for Learning: Appropriating Adventure Game Design Narrative Devices and Techniques for the Design of Interactive Learning Environments", Educational Technology Research and Development, Vol. 54, No. 3, pp 245-263.

Dickey, M.D. (2011) "Murder on Grimm Isle: The impact of game narrative design in an educational game-based learning environment", British Journal of Educational Technology, Vol. 42, No. 3, pp 456-469.

Field, S. (2005) Screenplay - The Foundations of Screenwriting, Revised Edition, Delta, New York.

Fiore, S., Metcalf, D. \& McDaniel, R. (2007) "Theoretical Foundations of Experiential Learning", In M. Silberman (ed.), The Handbook of Experiential Learning, John Wiley and Sons, San Francisco, pp 33-58.

Fludernik, M. (2009) An Introduction to Narratology, Routledge, London.

Freire, P. (1970) Pedagogy of the oppressed. Continuum., New York, NY.

Gee, J.P. (2003) "What video games have to teach us about learning and literacy". ACM Computers in Entertainment (CIE), Vol. 1, No. 1.

Gervás, P. (2009) “Computational Approaches to Storytelling and Creativity”, Al Magazine, Vol. 30, No. 3, pp 49-62.

Göbel, S. et al. (2009) "Narrative Game-based Learning Objects for Story-based Digital Educational Games", In M. D. Kickmeier-Rust (ed.), Proceedings of the 1st International Open Workshop on Intelligent Personalization and Adaptation in Digital Educational Games, pp 43-53.

Göbel, S., \& Mehm, F. (2013) “Personalized, Adaptive Digital Educational Games using Narrative Game-Based Learning Objects", In K. Bredl, \& W. Bösche (eds.), Serious Games and Virtual Worlds in Education, Professional Development, and Healthcare, IGI Global, Hershey, PA, pp 74-84.

Gray, C.M. (2015) “Critiquing the Role of the Learner and Context in Aesthetic Learning Experiences", In B. Hokanson, G. Clinton, \& M. W. Tracey (eds.), The Design of Learning Experience, Springer, New York, pp 199-213.

Hasenknopf, B., Michou, V., Milani, M., Perović, N., Young, C. (2019) Sharing the ABC approach to learning design across three European universities, European Learning \& Teaching Forum 2019, Warsaw, Poland, February 14-15, 2020.

Huang, H. M. (2002) "Toward constructivism for adult learners in online learning environments", British journal of educational technology, Vol. 33, No. 1, pp 27-37.

Jarrett, K. (2019) "Developing the art of storytelling as a pedagogical tool for academics", Articles from the 2018 University of Brighton Learning and Teaching Conference, Brighton, UK.

Johnson, L.F. et al. (2009) "Challenge-based learning: An approach for our time, The New Media Consortium, pp 1-38.

Johnson, L.F., \& Brown, S. (2011) "Challenge based learning: The report from the implementation project", The New Media Consortium, pp 1-36.

Kennedy, D. M. (2004) "Standards for online teaching: Lessons from the education, health and IT sectors", Nurse Education Today, Vol. 25, pp 23-30. 
Knowlton, D. S. (2000) "A theoretical framework for the online classroom: A defense and delineation of a student-centered pedagogy", New Directions for Teaching and Learning, Vol. 84, pp 5-14.

Lalonde, C. (2011) "Courses that deliver: Reflecting on constructivist critical pedagogical approaches to teaching online and on-site foundations courses", International Journal of Teaching and Learning in Higher Education. Vol. 23, No. 3, pp 408-423.

Laurillard, D. (2012). Teaching as a Design Science: Building Pedagogical Patterns for Learning and Technology. Routledge, New York and London.

Lindgren, R., \& McDaniel, R. (2012), "Transforming online learning through narrative and student agency", Educational Technology \& Society, Vol. 15, No. 4, pp 344-355.

Lindley, C.A. (2002) "The Gameplay Gestalt, Narrative, and Interactive Storytelling", In Proceedings of the Computer Games and Digital Cultures Conference, June 6-8, 2002, Tampere, Finland.

Lindley, C.A. (2005) "Story and narrative structures in computer games", In B. Bushoff (ed), Developing Interactive Narrative Content, High Text Verlag.

Louchart, S. \& Aylett, R. (2004) "Narrative theory and emergent interactive narrative", Int. J. Continuing Engineering Education and Lifelong Learning, Vol. 14, No. 6, pp 506-518.

Malone, T.W. (1981) "Toward a theory of intrinsically motivating instruction", Cognitive Science, Vol. 5, No. 4, pp 333-369.

Malone, T.W. \& Lepper, M.R. (1987) "Making Learning Fun: A Taxonomy of Intrinsic Motivations for Learning", In R. E. Snow \& M. J. Farr ( eds.), Aptitude, learning, and instruction - Conative and affective process analyses. Hillsdale, New Jersey, pp 223-253.

Matthews, M.T. (2018) “Designing for Narrative-Like Learning Experiences”, In B. Hokanson, G. Clinton, \& K. Kaminski (eds.), Educational Technology and Narrative, Springer, Cham, pp 249-258.

McCrory, R., Putnam, R. \& Jansen, A., (2008) "Interaction in online courses for teacher education: Subject matter and pedagogy”, Journal of Technology and Teacher Education, Vol. 16, No. 2, pp 155-180.

McFarland, K. (2017) “Entrepreneurship Education and Experiential E-Learning: A Literature Review”, Developments in Business Simulation and Experiential Learning, Vol. 44, pp 267-273.

Murphrey, T.P. (2010) "A case study of eelearning: Using technology to create and facilitate experiential learning", Quarterly Review of Distance Education, Vol. 11, No. 4, pp 211-221.

Nichols, M., \& Cator, K. (2008) “Challenge Based Learning”, White Paper, Cupertino, California: Apple.

Parrish, P.E. (2009) "Aesthetic principles for instructional design", Educational Technology Research and Development, Vol. 57, No. 4, pp 511-528.

Polkinghorne, Donald E. (1988) Narrative Knowing and the Human Sciences, State, University of New York Press, Albany.

Prensky, M. (2001) Digital game-based learning. McGraw-Hill, New York

Provenzo, E. F. (1991) Video kids: making sense of Nintendo. Harvard University Press, Cambridge, MA.

Recke, M. P. \& Perna, S. (2020a) "Application of Narrative Theory in Project Based Software Development Education", 15th European Conference on Innovation and Entrepreneurship (ECIE20), Rome, Italy, September 17-18, 2020.

Recke, M. P. \& Perna, S. (2020b) “Emergent Narratives In Project Based Software Development Education”, 14th European Conference on Games Based Learning (ECGBL20), Brighton, UK, September 24-25, 2020.

Recke, M. P. \& Perna, S. (2020c) “Narratively Driven Educational Experiences in Remote Learning Scenarios”, 19th Euopean Conference on e-Learning (ECEL 2020), Berlin, Germany, October 28-30, 2020.

Reigeluth, C.M. (1979) "In search of a better way to organize instruction: The elaboration theory", Journal of Instructional Development, Vol 2, No 3, pp 8-15.

Reigeluth, C.M. (1999) “The elaboration theory: Guidance for Scope and Sequences Decisions", In C.M. Reigeluth (Ed.), Instructional-Design Theories and Models: A New Paradigm of Instructional Theory, Volume II, Erlbaum Associates, Mahwah, NJ.

Reigeluth, C.M. (2012) "Instructional theory and technology for a post-industrial world", In R.A. Reiser \& J.V. Dempsey (Eds.), Trends and Issues in Instructional Design and Technology (3rd ed.), Pearson Education, Boston, MA, pp 75-83.

Rieber, L.P. (1996) "Seriously considering play: designing interactive learning environments based on the blending of microworlds, simulations, and games", Educational Technology Research and Development, Vol. 44, No. 2, pp 43-58.

Riedel, E., Endicott, L., Wasescha, A. \& Golston, B., (2007) “Continuous, interactive, and online: A framework for experiential learning with working adults", Innovate: Journal of Online Education, Vol. 3, No. 6.

Riedl, M.O. \& Bulitko, V. (2012) “Interactive Narrative: An Intelligent Systems Approach” AI Magazine, Vol 34, No. 1, pp 6767.

Rivera, J.C. \& Rice, M.L. (2002) “A comparison of student outcomes and satisfaction between traditional and web based course offerings", Online Journal of Distance Learning Administration, Vol. 5, No. 3, pp 151-179.

Schott, M., Chernish, W., Dooley, K.E. \& Lindner, J.R. (2003) "Innovations in distance learning program development and delivery", Online Journal of Distance Learning Administration, Vol. 6, No. 2, pp 19-27.

Shin, M., \& Lee, Y. J. (2009) "Changing the landscape of teacher education via online teaching and learning", Techniques: Connecting Education and Careers, Vol. 84, No. 1, pp 32-33.

Silbermann, M. (2006) Active Training - A Handbook of Techniques, Designs, Case Examples and Tips, 3rd Edition, Pfeiffer, San Francisco.

Skouge, J.R. \& Rao, K. (2009) "Digital Storytelling in Teacher Education: Creating Transformations through Narrative", Educational Perspectives, Vol 42, No, 1-2, pp 54-60. 
Sluijsmans, D., Dochy, F., \& Moerkerke, G. (1998) “Creating a learning environment by using self-, peer-and coassessment", Learning environments research, Vol. 1, No 3, pp 293-319.

Squire, K. (2002) "Cultural framing of computer/video games", The International Journal of Computer Game Research, Vol 2, No. 1.

Trevitte, C. \& Eskow, S., (2007) "Reschooling society and the promise of ee-learning: An interview with Steve Eskow", Innovate: Journal of Online Education, Vol. 3, No. 6.

Vogler, C. (1998) The Writer's Journey: Mythic Structure For Writers, Michael Wiese Productions, Studio City, CA.

Weinstein, C. E., Meyer, D., \& Husman, M. (2006) "Teaching students how to become more strategic and self-regulated learners", In W. J. McKeachie \& M. Svinicki (Eds.), McKeachie's teaching tips: Strategies, research and theory for college and university teachers (12th ed., pp. 300-317). Houghton Mifflin, Boston, MA.

Wiggins, G \& McTighe, J. (2005) Understanding by Design. ASCD. Alexandria, VA.

Wong, D., (2007) "A critical literature review on e-learning limitations", Journal for the Advancement of Science \& Arts, Vol. 2, pp 55-62, School of Management \& Information Technology, UCSI, Carseland.

Woodhouse, H. (2011) "Storytelling in University Education: Emotion, Teachable Moments, and the Value of Life", The Journal of Educational Thought (JET) / Revue De La Pensée Éducative, Vol. 45, No. 3, pp 211-238.

$\mathrm{Wu}, \mathrm{W}$.-H. et al. (2011) "Investigating the learning-theory foundations of game-based learning: a meta-analysis", Journal of Computer Assisted Learning, Vol. 28, No. 3, pp 265-279. 